\title{
Myrrh attenuates oxidative and inflammatory processes in acetic acid-induced ulcerative colitis
}

\author{
AMAL JAMIL FATANI ${ }^{1}$, FATIMA SALIH ALROJAYEE ${ }^{2}$, MIHIR YOGESHKUMAR PARMAR ${ }^{1}$, \\ HATEM MUSTAFA ABUOHASHISH ${ }^{1,3}$, MOHAMMED MAHBOOBUDDIN AHMED ${ }^{1}$ and SALIM SALIH AL-REJAIE ${ }^{1}$ \\ ${ }^{1}$ Department of Pharmacology and Toxicology, College of Pharmacy, King Saud University, Riyadh 11451; \\ ${ }^{2}$ Department of Internal Medicine, Medical School, Al Maareefa Colleges, Riyadh 11461; \\ ${ }^{3}$ Department of Biomedical Dental Sciences, College of Dentistry, University of Dammam, Dammam 31441, Saudi Arabia
}

Received March 4, 2015; Accepted May 11, 2016

DOI: 10.3892/etm.2016.3398

\begin{abstract}
The pathogenesis of ulcerative colitis (UC) has been associated with a weakened antioxidant capacity and increased inflammatory processes. Myrrh is traditionally used for the treatment of inflammatory diseases due to its antioxidant and anti-inflammatory properties. The present study aimed to evaluate the effects of myrrh on an experimental rat model of UC. UC was induced in rats using acetic acid (AA) after pre-treatment with myrrh $(125,250$ or $500 \mathrm{mg} / \mathrm{kg} / \mathrm{day})$ or mesalazine (MES; $300 \mathrm{mg} / \mathrm{kg} /$ day) for 7 days. The levels of various inflammatory cytokines, prostaglandin $\mathrm{E}_{2}\left(\mathrm{PGE}_{2}\right)$ and nitric oxide (NO) in the rat colon tissues were assessed. In addition, the colonic levels of thiobarbituric acid reactive substances (TBARS) and non-protein sulfhydryl groups (NP-SH), as well as the activities of superoxide dismutase (SOD) and catalase (CAT), were estimated. Furthermore, total protein (TP) contents and the levels of DNA and RNA were measured, and histopathological changes in colonic tissues were analyzed. The results indicated that the levels of pro-inflammatory cytokines, $\mathrm{PGE}_{2}$, $\mathrm{NO}$ and TBARS were markedly increased. By contrast, the levels of interleukin-10, NP-SH, TP and nucleic acids, and the enzymatic activities of SOD and CAT were significantly decreased in the AA model group. In addition, pretreatment with myrrh and MES was able to attenuate the impaired oxidative stress response and upregulation of inflammatory biomarkers. Furthermore, the enzymatic activities of SOD and CAT were near to normal in the myrrh and MES pretreated groups. The ability of myrrh to protect against UC was further confirmed by histopathological analysis, and the high dose of myrrh exerted an effect comparable to MES. In conclusion, the results of the present
\end{abstract}

Correspondence to: Professor Salim Salih Al-Rejaie, Department of Pharmacology and Toxicology, College of Pharmacy, King Saud University, 21 Abdullah Road, Riyadh 11451, Saudi Arabia E-mail: rejaie@ksu.edu.sa

Key words: Commiphora molmol, ulcerative colitis, oxidative stress, inflammatory bowel diseases, acetic acid study suggested that myrrh has potent therapeutic value in the amelioration of experimental colitis in laboratory animals by downregulating the expression of proinflammatory mediators and improving endogenous antioxidative activities.

\section{Introduction}

Inflammatory bowel diseases (IBDs) comprise ulcerative colitis (UC) and Crohn's disease (1), both of which have a high incidence in developed countries and severely affect the quality of life of patients worldwide (2). IBDs, which are complex and multifactorial diseases caused by diverse pathophysiological mechanisms, have numerous clinical manifestations, including abdominal pain, diarrhea, blood in the stool and weight loss (1). Persistent UC has been associated with an increased risk of developing colorectal cancer by $\sim 10$-fold (3). $\mathrm{UC}$ is characterized by excessive inflammation and oxidative stress $(4,5)$, which is considered a key factor in the pathogenesis and perpetuation of mucosal damage. Pro-inflammatory cytokines are secreted by macrophages and are responsible for the generation of reactive oxygen species (ROS), which activate the oxidative stress response and thus serve a vital role in the development and maintenance of IBD $(6,7)$. It has been demonstrated that oxidative injury results from the overproduction of free radicals, which leads to the lipid peroxidation (LPO) of membranes and the impairment of cellular proteins and nucleic acids (8). In addition, the generation of ROS and subsequent LPO reduces the cellular antioxidant capacity, which may lead to colonic inflammation (5).

Nitric oxide (NO), an intracellular mediator released by inducible nitric oxide synthase, is able to interact with free radicals to precipitate tissue damage (9). Prostaglandin $\mathrm{E}_{2}$ $\left(\mathrm{PGE}_{2}\right)$ is a pro-inflammatory mediator in the colon, and its upregulation has been associated with the inflammatory process (10). Various murine models of colitis have been developed over the past 20 years and are indispensable tools for elucidating the mechanisms underlying IBD pathogenesis, as well as for assaying potential therapeutics (11). The acetic acid (AA)-induced colitis model, which is similar to human UC in terms of its histological features, has been widely used to investigate the effects of various herbal therapies on experimental colitis $(12,13)$. 
The genus Commiphora (Burseraceae), which includes $>150$ plant species, is distributed in the tropical and subtropical regions, in particular within northeastern Africa, southern Arabia and India (14). Commiphora molmol Engl. is the main plant used in the production of myrrh, which is a oleo-gum-resin (OGR) made from dried tree sap that is traditionally used as a perfume, incense or embalming ointment (15). Previous studies have reported the beneficial effects of myrrh, which include anti-inflammatory, antispasmodic, antirheumatic, antipyretic, antiseptic and antihistaminic properties (16-18). In addition, purified metabolites of myrrh crude extracts have been investigated for antiproliferative, antimicrobial, hepatoprotective and cardiovascular properties (19). Experimentally, myrrh has demonstrated antigastric ulcer (20), anti-oxidative, cytotoxic and non-mutagenic properties in various studies $(21,22)$. Su et al (23) reported that myrrh significantly inhibited the production of $\mathrm{PGE}_{2}$ in carrageenan-induced paw edema in mice and exhibited potent anti-inflammatory effects. Therefore, the present study aimed to evaluate the ability of myrrh to protect against AA-induced UC in a rat model by measuring potential oxidative markers and inflammatory mediators known to damage the colonic tissues.

\section{Materials and methods}

Animals. The current study was performed using 36 male Wistar albino rats (age, 12 weeks; weight, 250-280 g) that were obtained from the Experimental Animal Care Center of King Saud University (Riyadh, Saudi Arabia). The rats were maintained at $25^{\circ} \mathrm{C}$ under a 12 -h light/dark cycle with ad libitum access to Purina rat chow (Grain Silos and Flour Mills Organization, Riyadh, Saudi Arabia) and water. All experimental and euthanasia procedures were performed in accordance with the National Institute of Health Guide for the Care and Use of Laboratory Animals (NIH Publications No. 80-23; 1996), as well as the Ethical Guidelines of the Experimental Animal Care Center of King Saud University.

Plant material and phytochemical screening. Authenticated myrrh was purchased from the local market in Riyadh, Saudi Arabia. For the purpose of maintaining experimental institutional records, the voucher specimen of the myrrh OGR was housed in the Herbarium at the College of Pharmacy of King Saud University. Chemical tests to identify the constituents of myrrh were performed using the aqueous extract, according to a standard procedure $(24,25)$. A yield of $9.72 \%$ essential oil was obtained by steam distillation $(23.17 \%)$ from the volatile oil. The presence of terpenes, sesquiterpenes, ester, cuminic, aldehyde and eugenol was detected.

Chemicals. Mesalazine (MES) was obtained from Shire (Lexington, MA, USA). The thiobarbituric acid reactive substances (TBARS) assay kit (0801192) was purchased from ZeptoMetrix Corp. (Buffalo, NY, USA). Tumor necrosis factor- $\alpha$ (TNF- $\alpha$; RTA00), interleukin (IL)-1 $\beta$ (RLB00), IL-6 (R6000B), IL-10 (M1000B), PGE 2 (KGE004B) and NO (KGE001) ELISA kits were purchased from R\&D Systems, Inc. (Minneapolis, MN, USA). All other chemicals used were of analytical reagent grade.
Experimental procedure. The rats were randomly allocated into five groups (6 rats per group), as follows: i) Control; ii) AA model; iii) myrrh (125 mg/kg/day) plus AA; iv) myrrh (250 mg/kg/day) plus AA; v) myrrh (500 mg/kg/day) plus AA; and vi) MES (300 mg/kg/day) plus AA. MES was used as a positive control against which to compare the effect of myrrh on UC. Pretreatment with myrrh or MES was conducted for 7 consecutive days by gavage. The doses used in the present study were selected based on an earlier study (20). At $24 \mathrm{~h}$ after the final treatment, UC was induced in all AA groups by administration of AA. After 1 day, the rats were sacrificed by decapitation under deep ether anesthesia $(10 \mathrm{ml} / \mathrm{l}$ air), and 5-6-cm specimens of the rat colons were dissected, washed with saline solution and weighed. A small $5-\mu \mathrm{m}$-thick cross section of the colon tissue from each group was fixed in $10 \%$ formaldehyde solution for histopathological analysis. The remaining colonic tissues were maintained at $-75^{\circ} \mathrm{C}$ for biochemical analysis.

Induction of $U C$. Experimental induction of $\mathrm{UC}$ in the rat colons was performed according to a previous study (26), with minor modifications. Briefly, the rats were transrectally administered $2 \mathrm{ml} 4 \%$ AA solution (v/v; Merck Millipore, Darmstadt, Germany) under light ether anesthesia (5 ml/1 air) using a 2.7-mm soft pediatric catheter. Following AA administration, the rats were held horizontally for 2 min to prevent AA leakage. The control rats underwent the same procedure using an equal volume of normal saline instead of AA solution.

Analysis of the adherent colonic mucus concentration. The concentration of colon adherent mucus was estimated according to a method described previously (27). Briefly, small $5-\mu \mathrm{m}$-thick sections of the rat colonic tissues were transferred immediately following weighing to a mixture of $1 \%$ Alcian blue and $0.16 \mathrm{~mol} / \mathrm{l}$ sucrose solution $(\mathrm{pH} 5)$ for $24 \mathrm{~h}$. The sucrose solution was used to rinse the excess dye, after which the dye bound to the colonic wall mucus was extracted using $0.5 \mathrm{~mol} / \mathrm{MgCl}_{2}$ and mixed with diethyl ether (1:1 ratio). The sample was then centrifuged at $1,800 \mathrm{x} g$ for $15 \mathrm{~min}$ at room temperature and the absorbance of the aqueous layer was detected at $580 \mathrm{~nm}$ using a Pharmacia-LKB UV-M II spectrophotometer (GE Healthcare Life Sciences, Marlborough, MA, USA) and a standard curve. Subsequently, the quantity of Alcian blue extracted in $\mu \mathrm{g} / \mathrm{g}$ of the wet colon was determined.

Determination of MDA levels in the rat colons. The levels of malondialdehyde (MDA), an LPO product, in the rat colon tissues were detected using the TBARS assay kit. Briefly, $100 \mu \mathrm{l}$ colon tissue homogenate was mixed with $2.5 \mathrm{ml}$ kit reaction buffer, followed by heating at $95^{\circ} \mathrm{C}$ for $1 \mathrm{~h}$. The sample was left to cool, centrifuged at $1,800 \mathrm{x} \mathrm{g}$ for $15 \mathrm{~min}$ at room temperature, and then a Pharmacia-LKB UV-M II spectrophotometer was used to measure the absorbance of the supernatant at $532 \mathrm{~nm}$ using a standard curve. The MDA levels in the colonic tissue are expressed in terms of $\mathrm{nm} / \mathrm{mg}$ protein.

Determination of non-protein sulfhydryl groups (NP-SH) concentration in the rat colons. The colonic concentration of NP-SH was determined according to the method described by Sedlak and Lindsay (28). Briefly, the homogenate was mixed 
A

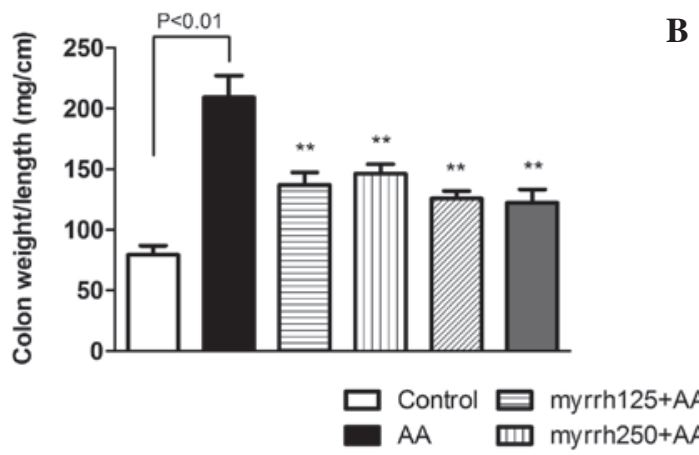

B

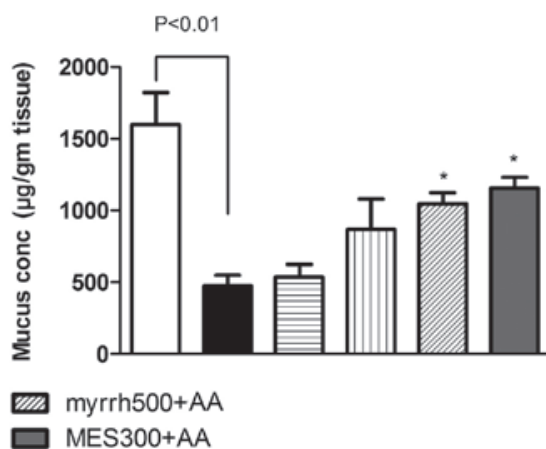

Figure 1. Effect of myrrh on the (A) weight/length ratio and (B) mucus content (mg/g) of colonic tissue from AA-induced ulcerative colitis rats. Data are expressed as the mean \pm standard error of the mean $(n=6)$ and analyzed using one-way analysis of variance followed by Student-Newman-Keuls multiple comparisons test. The AA group was compared with the control group, while the myrrh and MES-treated groups were compared with the AA group. ${ }^{*} \mathrm{P}<0.05$ and ${ }^{* *} \mathrm{P}<0.01$ vs. the AA group. AA, acetic acid; MES, mesalazine.

with $1 \mathrm{ml} \mathrm{50 \%} \mathrm{trichloroacetic} \mathrm{acid} \mathrm{(TCA),} \mathrm{followed} \mathrm{by} \mathrm{inter-}$ mittent shaking for $10-15 \mathrm{~min}$ and centrifugation at $1,350 \mathrm{x} \mathrm{g}$ for $15 \mathrm{~min}$ at room temperature. The supernatant was mixed with $0.4 \mathrm{~mol} / 1$ Tris buffer ( $\mathrm{pH} 8.9$ ) in a ratio of $1: 2$, followed by the addition of $0.1 \mathrm{ml}$ DTNB. The absorbance of the mixture was measured within $5 \mathrm{~min}$ at $412 \mathrm{~nm}$ using a Pharmacia-LKB UV-M II spectrophotometer and a standard curve.

Determination of superoxide dismutase (SOD) and catalase (CAT) activities in the rat colons. To obtain the post-mitochrondrial supernatant, $200 \mathrm{mg}$ colon tissue was homogenized in $2.0 \mathrm{ml}$ of $50 \mathrm{mM}$ phosphate buffered saline $(\mathrm{pH} 7.4)$ using a Pyrex glass pestle tissue grinder. Homogenates were centrifuged at $1,000 \mathrm{x} \mathrm{g}$ for $10 \mathrm{~min}$ at $4^{\circ} \mathrm{C}$ to separate the nuclei and unbroken cells. Pellets were discarded and the supernatant was again centrifuged at $12,000 \mathrm{x}$ g for $20 \mathrm{~min}$ at $4^{\circ} \mathrm{C}$. The enzymatic activity of the antioxidant enzyme SOD was measured in the post-mitochondrial supernatant of the colon homogenate according to a previous study by Kono (29). Briefly, superoxide anions generated by hydroxylamine hydrochloride oxidation mediated the reduction of nitro-blue tetrazolium to a blue formazan, which was then measured at $560 \mathrm{~nm}$ under aerobic conditions. SOD is known to inhibit nitro-blue tetrazolium reduction, and thus the extent of inhibition was used as a measure of SOD activity, which is expressed as units/mg protein (30). The enzymatic activity of CAT was measured using a method described previously (31). Briefly, the post-mitochondrial supernatant of the colon homogenate was mixed with $50 \mathrm{mmol} / 1$ phosphate buffer $(\mathrm{pH}$ 7.0) and $20 \mathrm{mmol} / 1 \mathrm{H}_{2} \mathrm{O}_{2}$. The enzymatic activity of CAT was then determined according to the decrease in absorbance at $240 \mathrm{~nm}$, and is expressed in terms of units/mg protein.

Determination of DNA, RNA and total protein (TP) levels in the rat colons. The DNA and RNA concentrations in the rat colon tissues were estimated according to a previously described method by Bregman (32). Briefly, the homogenized colon tissues were suspended in $5 \mathrm{ml}$ of $10 \%$ ice-cold TCA, after which the samples were centrifuged at $450 \mathrm{x} g$ for $3 \mathrm{~min}$ at room temperature and the resulting pellets were extracted twice using 95\% ethanol. Next, the nucleic acid content was extracted using 5\% TCA. For DNA quantification, diphenylamine reagent was added to the extracts, and the resulting blue color was measured at $600 \mathrm{~nm}$. For RNA determination, orcinol reagent was added to the extracts and the intensity of the green color was measured at $660 \mathrm{~nm}$. In addition, the Lowry method (33) was used to determine the TP content in the colon tissues, using bovine plasma albumin (BDH Chemicals, Poole, $\mathrm{UK}$ ) as a standard.

Determination of levels of inflammatory biomarkers in the rat colon tissues. The levels of TNF- $\alpha$, IL-10, IL-1 $\beta$, IL-6, PGE and NO in the rat colon tissues were determined using ELISA kits, according to a previous study by Mousavizadeh et al (26). The results are expressed as $\mathrm{pg} / \mathrm{mg}$ protein.

Histopathological analysis of $U C$. Cross sections of the rat colon tissues were fixed in $10 \%$ formaldehyde solution, embedded in paraffin wax blocks and cut into $5-\mu \mathrm{m}$ sections using a microtome. Samples were then stained with hematoxylin and eosin, mounted and observed under a light microscope. Histopathological sections were graded with scores of 0-4 according to inflammatory cellular infiltration, surface ulceration and necrosis, edema and hyperemia, and goblet cell hyperplasia. The scores demonstrated the percentage of damage or active changes, as follows: Score of $1,<25 \%$; score of $2,<50 \%$; score of $3,<75 \%$; and score of $4,>75 \%$ damage or active changes. The total score for the degree of colonic inflammation was determined, as follows: $<4$, minimal inflammatory changes; 4-8, mild inflammatory changes; 9-12, moderate inflammatory changes; and 13-16, severe inflammatory changes.

Statistical analysis. Data are expressed as the mean \pm standard error of the mean. Statistical analyses involved one-way analysis of variance followed by Student-Newman-Keuls post-hoc test, and were performed using GraphPad Prism software, version 5 (GraphPad Software, Inc., La Jolla, CA, USA). P $<0.05$ was considered to indicate a statistically significant difference.

\section{Results}

Effect of myrrh on colon weight/length ratio and mucus content in rats with AA-induced UC. The mean colonic weights were significantly increased in the AA group, as compared with the control group $(\mathrm{P}<0.01)$. As shown in Fig. 1A, 7 days of 


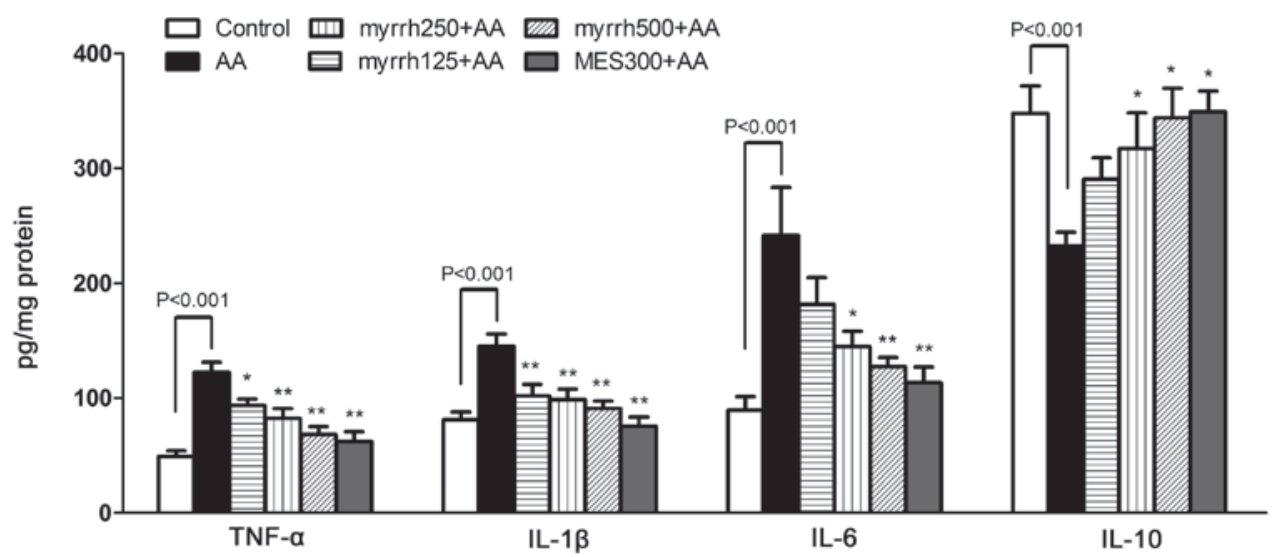

Figure 2. Effect of myrrh on the colonic levels of TNF- $\alpha$, IL-1 $\beta$, IL-6 and IL-10 in rats with AA-induced ulcerative colitis. Data are expressed as the mean \pm standard error of the mean $(n=6)$ and were analyzed using one-way analysis of variance, followed by Student-Newman-Keuls multiple comparisons test. The AA model group was compared with the control group, while the myrrh and MES-treated groups were compared with the AA group. "P<0.05 and ${ }^{* *} \mathrm{P}<0.01$ vs. the AA group. TNF- $\alpha$, tumor necrosis factor- $\alpha$; IL, interleukin; AA, acetic acid; MES, mesalazine.

A

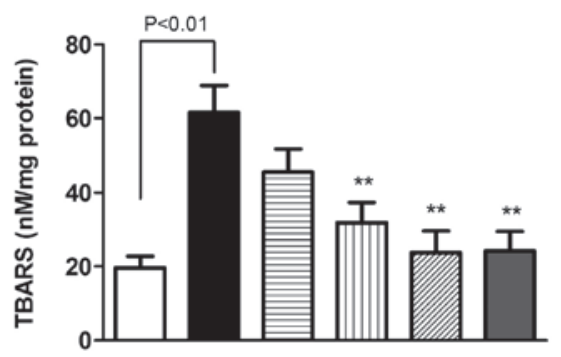

C

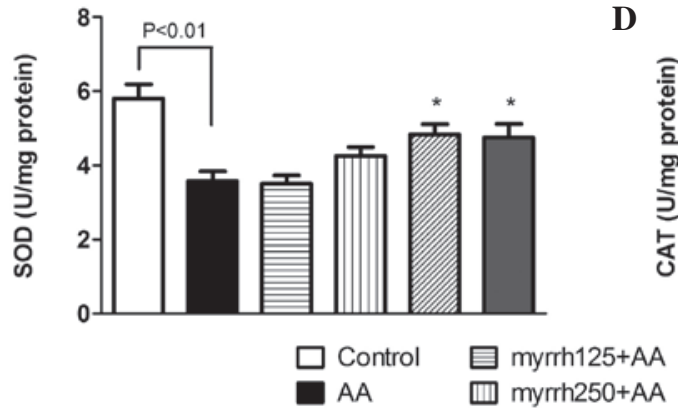

B
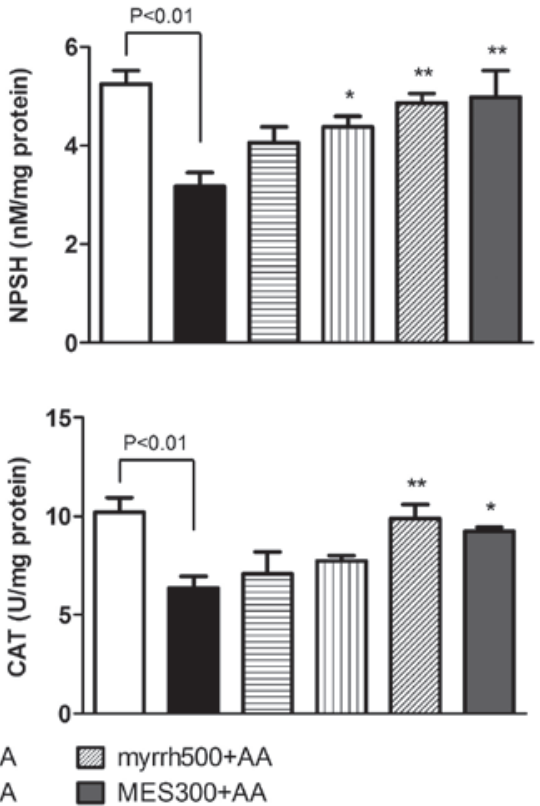

Figure 3. Effect of myrrh on colonic tissue levels of (A) TBARS and (B) NP-SH, and on the activities of (C) SOD and (D) CAT in rats with AA-induced ulcerative colitis. Data are expressed as the mean \pm standard error of the mean $(n=6)$ and were analyzed using one-way analysis of variance followed by Student-Newman-Keuls multiple comparisons test. The AA group was compared with the control group, while the myrrh and MES-pretreated groups were compared with the AA group. " $\mathrm{P}<0.05$ and ${ }^{* *} \mathrm{P}<0.01$ vs. the AA group. TBARS, thiobarbituric acid reactive substances; NP-SH, sulfhydryl groups; SOD, superoxide dismutase; CAT, catalase; AA, acetic acid; MES, mesalazine.

pretreatment with various doses of myrrh or $300 \mathrm{mg} / \mathrm{kg} /$ day MES resulted in a significant decline in the mean colon weights, as compared with the AA group $(\mathrm{P}<0.01)$. In addition, the rat colon mucus content was significantly decreased in the AA group, as compared with the control group $(\mathrm{P}<0.01)$. Pretreatment with a higher dose of myrrh $(500 \mathrm{mg} / \mathrm{kg} / \mathrm{day})$ or $300 \mathrm{mg} / \mathrm{kg} /$ day MES significantly increased the mucus content of the rat colons, as compared with the AA group $(\mathrm{P}<0.05$; Fig. 1B). These results suggest that myrrh has an anti-inflammatory and protective role against colon weight increase and gastric mucus depletion.

Effect of myrrh on the colonic levels of inflammatory cytokines in AA-induced UC rats. In the AA group, the levels of the pro-inflammatory cytokines TNF- $\alpha$, IL-1 $\beta$ and IL-6 were significantly increased, while the levels of the anti-inflammatory cytokine IL-10 were significantly decreased, as compared with the control group (all $\mathrm{P}<0.01$; Fig. 2). In the 250 and $500 \mathrm{mg} / \mathrm{kg} /$ day myrrh and MES pretreated groups, the levels of TNF- $\alpha$, IL-1 $\beta$ and IL- 6 were significantly decreased, as compared with the AA group $(\mathrm{P}<0.05$ and $\mathrm{P}<0.01)$. However, in the $125 \mathrm{mg} / \mathrm{kg} /$ day myrrh group, only the levels of TNF- $\alpha$ and IL-1 $\beta$, but not IL-6, were significantly decreased, as compared with the AA group. Furthermore, the levels of IL-10 were significantly increased in the 250 and $500 \mathrm{mg} / \mathrm{kg} /$ day myrrh and MES pretreated groups, as compared with the AA group $(\mathrm{P}<0.05$; Fig. 2$)$. These results demonstrated the anti-inflammatory property 
Table I. Effect of myrrh on the colonic levels of DNA, RNA and TP in rats with AA-induced ulcerative colitis.

\begin{tabular}{lccr}
\hline Group & DNA & RNA & TP \\
\hline Control & $524.7 \pm 33.03$ & $360.8 \pm 31.12$ & $3.4 \pm 0.22$ \\
AA & $192 \pm 20.38^{\mathrm{a}}$ & $159.1 \pm 20.75^{\mathrm{a}}$ & $1.31 \pm 0.19^{\mathrm{a}}$ \\
Myrrh (mg/kg/day) & & & \\
125 & $288.6 \pm 56.64$ & $194.9 \pm 27.09$ & $1.62 \pm 0.25$ \\
250 & $359.3 \pm 51.33$ & $225.3 \pm 17.13$ & $1.9 \pm 0.25$ \\
500 & $467.6 \pm 57.67^{\mathrm{b}}$ & $309.7 \pm 33.51^{\mathrm{b}}$ & $2.82 \pm 0.33^{\mathrm{c}}$ \\
MES (300 mg/kg/day) & $473.7 \pm 76.87^{\mathrm{b}}$ & $345.2 \pm 43.07^{\mathrm{b}}$ & $2.96 \pm 0.3^{\mathrm{c}}$ \\
\hline
\end{tabular}

Data are expressed as the mean \pm standard error of the mean $(n=6)$ and were analyzed using one-way analysis of variance followed by Student-Newman-Keuls multiple comparisons test. ${ }^{\mathrm{a}} \mathrm{P}<0.01$ vs. the control group; ${ }^{\mathrm{b}} \mathrm{P}<0.01$ and ${ }^{\mathrm{c}} \mathrm{P}<0.05$ vs. the AA group. TP, total protein; AA, acetic acid; MES, mesalazine.
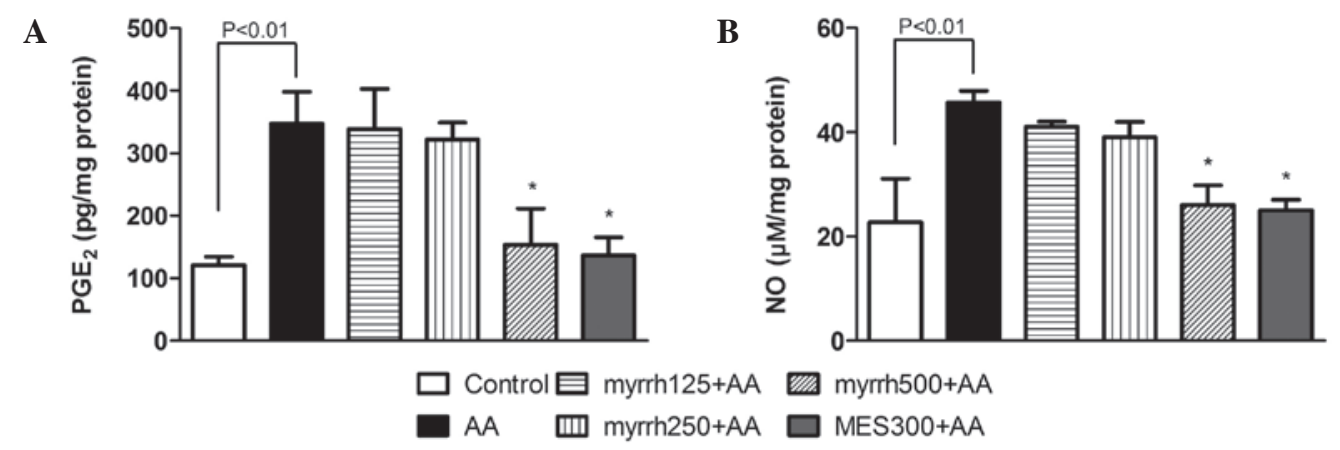

Figure 4. Effect of myrrh on the colonic tissue levels of (A) $\mathrm{PGE}_{2}$ and (B) NO in rats with AA-induced ulcerative colitis. Data are expressed as the mean \pm standard error of the mean $(n=6)$ and were analyzed using one-way analysis of variance, followed by Student-Newman-Keuls multiple comparisons test. The AA group was compared with the control group and the myrrh and MES-pretreated groups were compared with the AA group. ${ }^{*}<0.05$ vs. the AA group. PGE ${ }_{2}$, prostaglandin $\mathrm{E}_{2}$; NO, nitric oxide; AA, acetic acid; MES, mesalazine.

of myrrh, as myrrh pretreatment inhibited the expression of colonic proinflammatory cytokines.

Effect of myrrh on the colonic levels of TBARS and NP-SH, and on the activities of SOD and CAT in AA-induced UC rats. At $24 \mathrm{~h}$ following AA administration, TBARS levels were significantly increased in the AA group, as compared with the control rats $(\mathrm{P}<0.01)$. However, pretreatment with 250 and $500 \mathrm{mg} / \mathrm{kg} /$ day myrrh or with MES resulted in a significant decline in TBARS levels, as compared with the AA group ( $\mathrm{P}<0.01$; Fig. $3 \mathrm{~A})$. In addition, the levels of NP-SH were significantly decreased in the colon tissues of AA group rats, as compared with the control group $(\mathrm{P}<0.01)$. By contrast, the levels of NP-SH were significantly increased in rats pretreated with high doses of myrrh (250 and $500 \mathrm{mg} / \mathrm{kg}$ ) or $300 \mathrm{mg} / \mathrm{kg} \mathrm{MES}$, as compared with the AA group rats $(\mathrm{P}<0.05$; Fig. $3 \mathrm{~B})$. The results also indicated that the activities of the antioxidative enzymes SOD and CAT were significantly inhibited in the colons of AA-treated rats, as compared with those in control rats $(\mathrm{P}<0.01)$. Pretreatment with $500 \mathrm{mg} / \mathrm{kg} /$ day myrrh and MES resulted in significant increases in SOD and CAT activities, as compared with the AA group $(\mathrm{P}<0.05$; Fig. $3 \mathrm{C}$ and $\mathrm{D})$. These results demonstrated the antioxidative effect of myrrh, as myrrh pretreatment induced a marked reduction in TBARS levels, increased NP-SH and enhanced the enzymatic activities of SOD and CAT.
Effect of myrrh on colonic levels of nucleic acids and TP content in AA-induced UC rats. The levels of DNA, RNA and TP in the rat colon tissues were significantly decreased in the rats administered AA, as compared with the control rats $(\mathrm{P}<0.01)$. Pretreatment with myrrh $(500 \mathrm{mg} / \mathrm{kg})$ and $\mathrm{MES}$ resulted in significant increases in the levels of DNA $(\mathrm{P}<0.01)$, RNA $(\mathrm{P}<0.01)$ and TP $(\mathrm{P}<0.05)$, as compared with the AA group (Table I). These dose-dependent improvements in nucleic acid levels demonstrated the cytoprotective effects of myrrh.

Effect of myrrh on colonic levels of $\mathrm{PGE}_{2}$ and $\mathrm{NO}$ in $A A$-induced $U C$ rats. $\mathrm{PGE}_{2}$ and $\mathrm{NO}$ levels were significantly increased in the colonic cells of rats administered AA, as compared with the control rats $(\mathrm{P}<0.01)$. After 7 days of pretreatment with myrrh $(500 \mathrm{mg} / \mathrm{kg})$ or MES, a significant decrease was observed in the levels of $\mathrm{PGE}_{2}$ and $\mathrm{NO}$ in rat colon tissues, as compared with those in the AA group $(\mathrm{P}<0.05$; Fig. 4). These results suggested the anti-inflammatory potential of myrrh, as myrrh pretreatment induced a marked inhibition of the elevated levels of $\mathrm{PGE}_{2}$ and $\mathrm{NO}$ in colon tissue.

Effect of myrrh on histopathological changes in the colons of AA-induced UC rats. As shown in Table II and Fig. 5, a histopathological analysis of rat colon sections revealed minimal 
Table II. Effect of myrrh on histopathological changes in the colonic tissues of rats with AA-induced ulcerative colitis.

\begin{tabular}{|c|c|c|c|c|c|}
\hline Group & $\begin{array}{l}\text { Inflammatory cell } \\
\text { infiltration }\end{array}$ & $\begin{array}{l}\text { Surface ulceration } \\
\text { and necrosis }\end{array}$ & $\begin{array}{l}\text { Edema and } \\
\text { hyperemia }\end{array}$ & $\begin{array}{l}\text { Goblet cell } \\
\text { hyperplasia }\end{array}$ & Total score \\
\hline Control & 0 & 0 & 0 & 0 & 0 \\
\hline $\mathrm{AA}$ & 4 & 4 & 4 & 3 & 15 \\
\hline \multicolumn{6}{|l|}{ Myrrh (mg/kg/day) } \\
\hline 125 & 3 & 3 & 2 & 1 & 9 \\
\hline 250 & 2 & 2 & 2 & 2 & 8 \\
\hline 500 & 2 & 0 & 1 & 0 & 3 \\
\hline MES (300 mg/kg/day) & 1 & 1 & 1 & 0 & 3 \\
\hline
\end{tabular}

Sections were scored for inflammatory cell infiltration, surface ulceration and necrosis, edema and hyperemia and goblet cell hyperplasia, as follows: $1,<25 \%$ damage or active changes; $2,<50 \%$ damage or active changes; $3,<75 \%$ damage or active changes; and $4,>75 \%$ damage or active changes. A total score of $<4$ indicated minimal inflammatory changes, a score of 4-8 indicated mild inflammatory changes, a score of 9-12 indicated moderate inflammatory changes and a score of 13-16 indicated severe inflammatory changes. AA, acetic acid; MES, mesalazine.

A

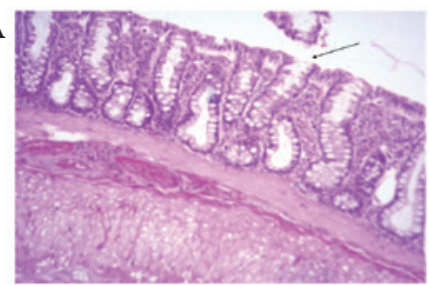

C

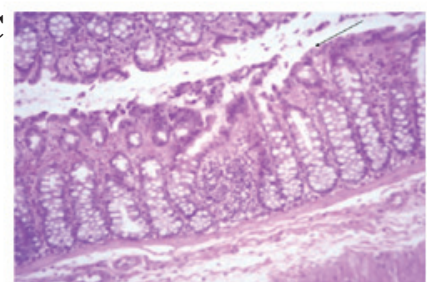

$\mathbf{E}$

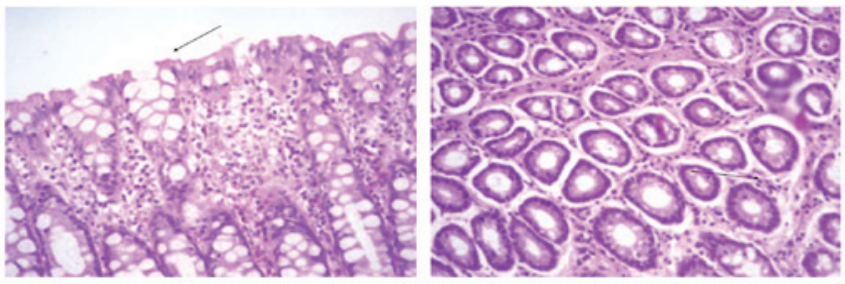

B
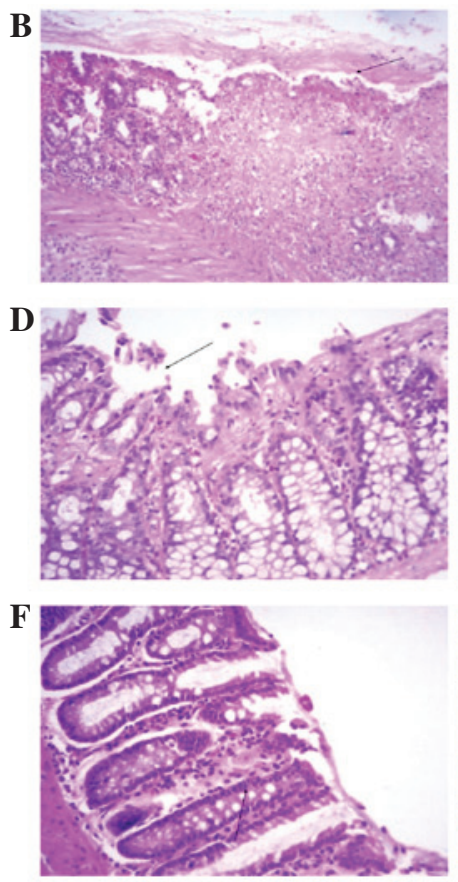
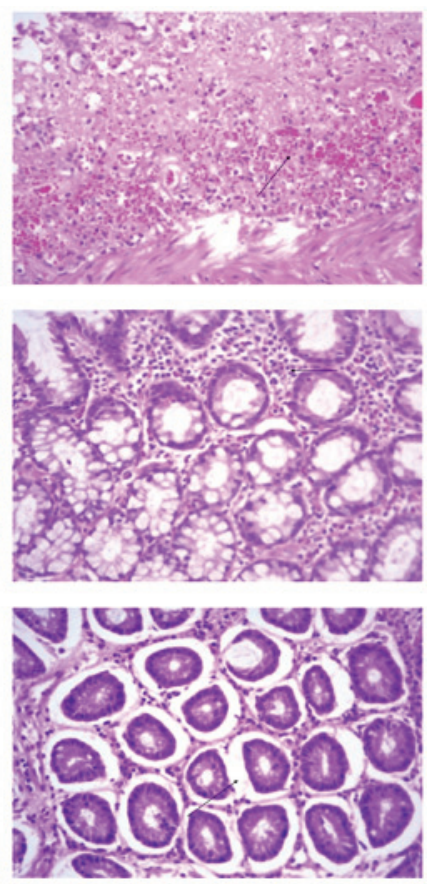

Figure 5. Histopathological examination of colonic sections (Left panels, magnification x10; right panels, magnification x20). (A) Minimal surface necrosis and ulceration (arrows) with no inflammatory cell infiltration, edema or hyperemia was observed in the control group. (B) Severe surface ulceration, necrosis, edema, hyperemia and inflammatory cell infiltration (arrows) was observed in the acetic acid-treated group. (C) Moderate surface necrosis, ulceration, edema, hyperemia and inflammatory cell infiltration (arrows) was observed in the $125 \mathrm{mg} / \mathrm{kg} / \mathrm{day}$ myrrh-treated group. (D) Mild surface necrosis, ulceration, inflammatory cell infiltration, edema and hyperemia (arrows) was observed in the $250 \mathrm{mg} / \mathrm{kg} / \mathrm{day}$ myrrh-treated group. (E) No evidence of surface ulceration or necrosis and minimal inflammatory cell infiltration, edema and hyperemia (arrows) was observed in the $500 \mathrm{mg} / \mathrm{kg} / \mathrm{day}$ myrrh-treated group. (F) Minimal focal surface necrosis, ulceration, edema, hyperemia and inflammatory changes (arrows) were observed in the $300 \mathrm{mg} / \mathrm{kg} / \mathrm{day}$ mesalazine-treated group.

inflammatory cell infiltration, surface necrosis and ulceration, as well as no evidence of edema, hyperemia or goblet cell hyperplasia, in the colons of the control group rats. Therefore, the clinical diagnosis was unremarkable pathological changes (Fig. 5A). Conversely, histopathological analysis in the AA group demonstrated diffused severe inflammatory cell infiltration with marked surface ulceration, necrosis, edema and hyperemia, as well as moderate goblet cell hyperplasia, and the clinical diagnosis was diffused severe inflammatory changes (Fig. 5B). Myrrh pretreatment appeared to exert a dose-dependent effect on the AA-induced histopathological changes in the rat colons. In rats pretreated with $125 \mathrm{mg} / \mathrm{kg} / \mathrm{day}$ myrrh, diffuse moderate inflammatory cell infiltration with focal moderate surface ulceration, necrosis, edema and hyperemia, as well as mild focal goblet cell hyperplasia, were observed, and the clinical diagnosis was focal moderate inflammatory changes (Fig. 5C). In the $250 \mathrm{mg} / \mathrm{kg} /$ day myrrh group, diffused mild inflammatory cell infiltration with focal surface necrosis and ulceration and moderate edema and hyperemia, as well as mild goblet cell hyperplasia, were 
observed, and the clinical diagnosis was focal mild inflammatory changes (Fig. 5D). In the $500 \mathrm{mg} / \mathrm{kg} /$ day myrrh group, the analysis revealed diffused mild inflammatory cell infiltration with minimal edema and hyperemia, with the absence of surface necrosis, ulceration and goblet cell hyperplasia. The clinical diagnosis for the $500 \mathrm{mg} / \mathrm{kg} / \mathrm{day}$ myrrh group was diffused minimal inflammatory changes (Fig. 5E). Similarly, pretreatment with $300 \mathrm{mg} / \mathrm{kg} /$ day MES resulted in minimal focal inflammatory changes, necrosis, ulceration, edema, hyperemia and goblet cell hyperplasia. The clinical diagnosis of this group was diffused minimal inflammatory changes (Fig. 5F).

\section{Discussion}

The present study aimed to investigate the protective effects of myrrh in a rat model of AA-induced UC. The AA-induced UC model, which is similar to human UC in terms of histological features, has been used in various previous studies $(12,34)$. The histopathological analysis performed in the present study demonstrated that AA treatment resulted in disruption of the entire colonic mucosa, erosion, ulceration, congestion, inflammation and necrosis. Pretreatment with myrrh at three different doses $(125,250$ or $500 \mathrm{mg} / \mathrm{kg} /$ day) for 7 days was shown to preserve the functional cytoarchitecture of the colon to varying extents. In addition, myrrh markedly protected against AA-induced loss of the colonic mucosal content and prevented colonic oxidative and inflammatory responses to AA in a dose-dependent manner. The present study also compared the anti-ulcerogenic effect of myrrh with a standard drug, MES. The effect of MES pretreatment was similar to that observed for the $500 \mathrm{mg} / \mathrm{kg} / \mathrm{day}$ myrrh pretreatment.

Under normal physiological conditions, the mucosa of the colon contains relatively low levels of endogenous antioxidants. Oxidative stress may inhibit the endogenous defense systems that regulate ROS production (35). High levels of ROS lead to oxidative stress and DNA damage due to an imbalance between innate and exogenous antioxidants and ROS $(36,37)$. In addition, it may promote the infiltration of leukocytes into the damaged area, the rupture of the colonic barrier, and the release of inflammatory mediators, including cytokines and arachidonic acid metabolites $(38,39)$. In the present study, the rectal administration of AA significantly increased the weight of the rat colon, and this was associated with severe tissue ulceration, inflammatory cell infiltration, necrosis and goblet cell hyperplasia, as demonstrated by the histopathological analysis. These results are consistent with those reported in previous studies using the same animal model $(40,41)$. Defects in the colonic mucosal barrier and functions are among the etiological factors that characterize IBDs (42). In the present study, the protective colonic mucus was markedly altered by AA, which is in line with earlier studies conducted in our labs $(43,44)$. Pretreatment with myrrh at various doses for 7 days significantly reduced the colon weight and inhibited colonic wall mucus depletion.

Oxidative stress is known to serve a major role in the initiation and progression of IBD $(45,46)$. A previous study reported vascular dilatation and white blood cell accumulation in an AA-induced model of IBD, which was associated with an increased blood flow and production of ROS (47). ROS attack cellular macromolecules, thereby disrupting epithelial cell integrity and hindering mucosal recovery, in particular in patients with an impaired endogenous defense system (48). Furthermore, the superoxide anion radical, hydrogen peroxide and hydroxyl radicals, which are secreted by neutrophils and phagocytes, accumulate in the inflammatory lesion, leading to destabilization of the cell membrane, cell death via LPO, and damage to tissue proteins and DNA $(49,50)$. TBARS, which are markers of LPO, interact with DNA and proteins leading to pathological changes (51). The present study demonstrated that myrrh was able to significantly reduce the levels of TBARS in the colonic tissues of rats administered AA, thereby disrupting the feedback loop and attenuating damage to colonic tissues. Endogenous antioxidants, such as NP-SH, and antioxidant enzymes, including SOD and CAT (52), serve a major role in preventing excessive free radical generation under pathogenic conditions. In the present study, the concentration of NP-SH and the activities of SOD and CAT were significantly reduced in the colon tissues of AA-treated rats. In addition, the levels of critical cellular macro- and micro-molecules, including nucleic acids and proteins, were decreased in the AA group rats. These results were consistent with our previous findings $(43,44)$, and indicated that AA was able to exert harmful effects on cellular macromolecules, impair epithelial cell integrity and hinder mucosal recovery.

IBD is a complex multi-factorial intestinal inflammatory disease, involving immunological, genetic and environmental factors (53). Pro-inflammatory mediators are able to modulate the mucosal immune system and disrupt the epithelial integrity by promoting the infiltration of neutrophils and macrophages (54). The migration of granulocytes and other leukocytes to the inflamed mucosa and superficial ulcers results in the overproduction of pro-inflammatory cytokines $(55,56)$, which is an indicator of the disease severity. In the coordinated network of inflammatory response, TNF- $\alpha$ serves an important signaling role in the inflammatory cascade following its secretion. Specifically, it activates monocytes, macrophages and intestinal immune cells in order to produce $\mathrm{PGE}_{2}$, proteases and chemotactic cytokines (57). IL-6 is a pleiotropic cytokine that has a central role in immune regulation and inflammation (58). IL-6-activated macrophages and colon epithelial cells secrete inflammatory cytokines, including TNF- $\alpha$ and IL-1 $\beta$, that contribute to the development of colitis (59). In the present study, the levels of IL-1 $\beta$, TNF- $\alpha$, IL- 6 , NO and PGE $_{2}$ were significantly increased in colon tissues of AA-treated rats. These results suggested that the colons of the AA-treated rats were inflamed, which was supported by the histopathological results. In addition, these results were consistent with those of previous experimental and clinical studies $(27,40,60,61)$.

In accordance with previous studies $(62,63)$, the antioxidant effects of myrrh were also demonstrated in the present study. The levels of NP-SH and the activities of SOD and CAT in rat colonic tissues were increased in myrrh-treated rats in a dose-dependent manner, with higher myrrh doses resulting in a greater effect. The cytoprotective and antioxidant effects of myrrh demonstrated in the present study may have been due to the presence of several pharmacologically active constituents. The distribution of 51 constituents and medical applications of 
Commiphora were reviewed in 2003 by El Ashry et al (19). myrrh contains volatile oil, which in turn consists of heerabolene, a-cadinene, elemol, eugenol, cuminaldehyde, terpenes (such as furanodiene, furanodienone, curzerenone, lindestrene, 2-methoxyfuranodiene and 3-epi-alpha-amyrin), and various other compounds (64). In addition, myrcene, a-camphorene and various steroids, including Z-guggulsterol and guggulsterol I, II and III, have been detected (65), while a previous study reported that tannins were also found in myrrh (66). Therefore, these antioxidative constituents may, at least in part, be responsible for the protective effect of myrrh pretreatment against AA-induced UC. Furthermore, the anti-inflammatory properties of myrrh have previously been reported (67). Consistent with this, the present study observed that AA treatment resulted in a marked reduction in the colonic levels of pro-inflammatory cytokines, including IL-1 $\beta$, IL- 6 and TNF- $\alpha$, which are principally responsible for causing oxidative damage (68). Therefore, it may be hypothesized that the anti-inflammatory effects of myrrh are regulated by its antioxidative activities.

In conclusion, the results of the present study provided support for the beneficial effects of myrrh against AA-induced experimental colitis. The protective properties of myrrh may be attributed to its ability to inhibit free radical production and potentiate the endogenous enzymatic or nonenzymatic antioxidant system. Furthermore, myrrh was shown to decrease the levels of inflammatory mediators, thus suggesting that it may have a role as an anti-inflammatory compound. The results of the present study suggest that myrrh may be a promising novel candidate compound for the treatment of IBDs.

\section{Acknowledgements}

The present study was supported by the Deanship of Scientific Research at King Saud University (grant no. RGP-VPP-103).

\section{References}

1. Safarpour AR, Hosseini SV and Mehrabani D: Epidemiology of inflammatory bowel diseases in iran and Asia; a mini review. Iran J Med Sci 38 (Suppl 2): S140-S149, 2013.

2. Xavier RJ and Podolsky DK: Unravelling the pathogenesis of inflammatory bowel disease. Nature 448: 427-434, 2007.

3. Mehrabani D, Tabei ST, Heydari SJ, Shamsina SJ, Shokrpour N, Amini M, Masoumi SJ, Julaee H, Farahmand M and Manafi A: Cancer occurrence in Fars Province, Southern Iran. Iran Red Crescent Med J 10: 314-322, 2008.

4. Cetinkaya A, Bulbuloglu E, Kantarceken B, Ciralik H, Kurutas EB, Buyukbese MA and Gumusalan Y: Effects of L-carnitine on oxidant/antioxidant status in acetic acid-induced colitis. Dig Dis Sci 51: 488-494, 2006.

5. Cetinkaya A, Bulbuloglu E, Kurutas EB, Ciralik H, Kantarceken B and Buyukbese MA: Beneficial effects of N-acetylcysteine on acetic acid-induced colitis in rats. Tohoku J Exp Med 206 131-139, 2005.

6. Seo HG, Takata I, Nakamura M, Tatsumi H, Suzuki K, Fujii J and Taniguchi N: Induction of nitric oxide synthase and concomitant suppression of superoxide dismutases in experimental colitis in rats. Arch Biochem Biophys 324: 41-47, 1995.

7. Larrick JW and Wright SC: Cytotoxic mechanism of tumor necrosis factor-alpha. FASEB J 4: 3215-3223, 1990.

8. Bertevello PL, Logullo AF, Nonogaki S, Campos FM, Chiferi V, Alves CC, Torrinhas RS, Gama-Rodrigues JJ and Waitzberg DL: Immunohistochemical assessment of mucosal cytokine profile in acetic acid experimental colitis. Clinics (Sao Paulo) 60: 277-286, 2005 .
9. PacherP, Beckman JS and Liaudet L: Nitric oxide and peroxynitrite in health and disease. Physiol Rev 87: 315-424, 2007.

10. Rachmilewitz D, Karmeli F, Okon E, Rubenstein I and Better OS: Hyperbaric oxygen: A novel modality to ameliorate experimental colitis. Gut 43: 512-518, 1998.

11. Chassaing B, Aitken JD, Malleshappa M and Vijay-Kumar M: Dextran sulfate sodium (DSS)-induced colitis in mice. Curr Protoc Immunol 104: Unit 15.25, 2014

12. Mehrabani D, Ziaei M, Hosseini SV, Ghahramani L, Bananzadeh AM, Ashraf MJ, Amini A, Amini M and Tanideh N: The effect of calendula officinalis in therapy of acetic Acid induced ulcerative colitis in dog as an animal model. Iran Red Crescent Med J 13: 884-890, 2011.

13. Redwan el-RM and Tabll A: Camel lactoferrin markedly inhibits hepatitis $C$ virus genotype 4 infection of human peripheral blood leukocytes. J Immunoassay Immunochem 28: 267-277, 2007.

14. Hanuš LO, Řezankab T, Dembitskya VM and Moussaieff A: Myrrh-Commiphora chemistry. Biomed Papers 149: 3-28, 2005.

15. Mugah JO, Chikamai BN, Mbiru SS and Casadei E: Conservation, management and utilization of plant gums, resins and essential oils. Proceedings of a Regional Conference for Africa (Nairobi, Kenya), 6-10 Oct, 1997.

16. Massoud A, El Sisi S, Salama O and Massoud A: Preliminary study of therapeutic efficacy of a new fasciolicidal drug derived from Commiphora molmol (myrrh). Am J Trop Med Hyg 65: 96-99, 2001.

17. Shalaby MA and Ashraf Hammouda AA: Analgesic, anti-inflammatory and anti-hyperlipidemic activities of Commiphora molmol extract (Myrrh) J Intercult Ethnopharmacol 3: 56-62, 2014.

18. El-Sherbiny GM and El Sherbiny ET: The effect of Commiphora molmol (Myrrh) in treatment of Trichomoniasis vaginalis infection. Iran Red Crescent Med J 13: 480-486, 2011.

19. El Ashry ES, Rashed N, Salama OM and Saleh A: Components, therapeutic value and uses of myrrh. Pharmazie 58: 163-168, 2003.

20. al-Harbi MM, Qureshi S, Raza M, Ahmed MM, Afzal M and Shah AH: Gastric antiulcer and cytoprotective effect of Commiphora molmol in rats. J Ethnopharmacol 55: 141-150, 1997.

21. al-Harbi MM, Qureshi S, Ahmed MM, Rafatullah S and Shah AH: Effect of Commiphora molmol (oleo-gum-resin) on the cytological and biochemical changes induced by cyclophosphamide in mice. Am J Chin Med 22: 77-82, 1994.

22. Qureshi S, al-Harbi MM, Ahmed MM, Raza M, Giangreco AB and Shah AH: Evaluation of the genotoxic, cytotoxic and antitumor properties of Commiphora molmol using normal and Ehrlich ascites carcinoma cell-bearing Swiss albino mice. Cancer Chemother Pharmacol 33: 130-138, 1993

23. Su S, Hua Y, Wang Y, Gu W, Zhou W, Duan JA, Jiang H, Chen T and Tang Y: Evaluation of the anti-inflammatory and analgesic properties of individual and combined extracts from Commiphora myrrha and Boswellia carterii. J Ethnopharmacol 139: 649-656, 2012.

24. Sofowora A: Medicinal plants and traditional medicine in Africa. John Wiley and Sons Ltd, Chichester, 1982.

25. AOAC: Official Methods of Analysis. 15th edition. Association of Official Analytical Chemists, Inc., Arlington, Virginia, 1990.

26. Mousavizadeh K, Rahimian R, Fakhfouri G, Aslani FS and Ghafourifar P: Anti-inflammatory effects of 5-HT receptor antagonist, tropisetron on experimental colitis in rats. Eur J Clin Invest 39: 375-383, 2009.

27. Popov SV, Markov PA, Nikitina IR, Petrishev S, Smirnov V and Ovodov YS: Preventive effect of a pectic polysaccharide of the common cranberry Vaccinium oxycoccos L. on acetic acid-induced colitis in mice. World J Gastroenterol 12: 6646-6651, 2006.

28. Sedlak J and Lindsay RH: Estimation of total, protein-bound, and nonprotein sulfhydryl groups in tissue with Ellman's reagent. Anal Biochem 25: 192-205, 1968.

29. Kono Y: Generation of superoxide radical during autoxidation of hydroxylamine and an assay for superoxide dismutase. Arch Biochem Biophys 186: 189-195, 1978.

30. Monk LS, Fagerstedt KV and Crawford RM: Superoxide dismutase as an anaerobic polypeptide: A key Factor in recovery from oxygen deprivation in Iris pseudacorus? Plant Physiol 85: 1016-1020, 1987.

31. Aebi H: Catalase. In: Methods of Enzymatic Analysis. Bergmeyer HU (ed.). Academic Press, New York, pp 674-684, 1974. 
32. Bregman AA: Laboratory Investigations in Cell Biology. John Wiley and Sons, New York, 1983.

33. Lowry OH, Rosebrough NJ, Farr AL and Randall RJ: Protein measurement with the Folin phenol reagent. J Biol Chem 193: 265-275, 1951

34. Mehrabani D, Bahrami F, Hosseini SV, Ashraf MJ, Tanideh N, Rezaianzadeh A, Amini M and Amini A: The healing effect of teucrium polium in acetic acid-induced ulcerative colitis in the dog as an animal model. Middle East J Dig Dis 4: 40-47, 2012.

35. Bhattacharyya A, Chattopadhyay R, Mitra S and Crowe SE: Oxidative stress: An essential factor in the pathogenesis of gastrointestinal mucosal diseases. Physiol Rev 94: 329-354, 2014.

36. Hemnani $\mathrm{T}$ and Parihar MS: Reactive oxygen species and oxidative DNA damage. Indian J Physiol Pharmacol 42: 440-452, 1998.

37. Rezaie A, Parker RD and Abdollahi M: Oxidative stress and pathogenesis of inflammatory bowel disease: An epiphenomenon or the cause? Dig Dis Sci 52: 2015-2021, 2007.

38. Pavlick KP, Laroux FS, Fuseler J, Wolf RE, Gray L, Hoffman J and Grisham MB: Role of reactive metabolites of oxygen and nitrogen in inflammatory bowel disease. Free Radic Biol Med 33: 311-322, 2002

39. Grisham MB: Oxidants and free radicals in inflammatory bowel disease. Lancet 344: 859-861, 1994.

40. El-Abhar HS, Hammad LN and Gawad HS: Modulating effect of ginger extract on rats with ulcerative colitis. J Ethnopharmacol 118: 367-372, 2008.

41. Harputluoglu MM, Demirel U, Yücel N, Karada ğ N, Temel I, Firat S, Ara C, Aladağ M, Karincaoğlu M and Hilmioğlu F: The effects of Gingko biloba extract on acetic acid-induced colitis in rats. Turk J Gastroenterol 17: 177-182, 2006.

42. Duerr RH: Update on the genetics of inflammatory bowel disease. J Clin Gastroenterol 37: 358-367, 2003.

43. Aleisa AM, Al-Rejaie SS, Abuohashish HM, Ola MS, Parmar MY and Ahmed MM: Pretreatment of Gymnema sylvestre revealed the protection against acetic acid-induced ulcerative colitis in rats. BMC Complement Altern Med 14: 49, 2014

44. Al-Rejaie SS, Abuohashish HM, Al-Enazi MM, Al-Assaf AH, Parmar MY and Ahmed MM: Protective effect of naringenin on acetic acid-induced ulcerative colitis in rats. World Gastroenterol 19: 5633-5644, 2013.

45. Patel MA, Patel PK and Patel MB: Effects of ethanol extract of Ficus bengalensis (bark) on inflammatory bowel disease. Indian J Pharmacol 42: 214-218, 2010.

46. Narushima S, Spitz DR, Oberley LW, Toyokuni S, Miyata T, Gunnett CA, Buettner GR, Zhang J, Ismail H, Lynch RG and Berg DJ: Evidence for oxidative stress in NSAID-induced colitis in IL10 ${ }^{-/}$mice. Free Radic Biol Med 34: 1153-1166, 2003.

47. Hartmann RM, Morgan Martins MI, Tieppo J, Fillmann HS and Marroni NP: Effect of Boswellia serrata on antioxidant status in an experimental model of colitis rats induced by acetic acid. Dig Dis Sci 57: 2038-2044, 2012

48. Buffinton GD and Doe WF: Depleted mucosal antioxidant defences in inflammatory bowel disease. Free Radic Biol Med 19: 911-918, 1995.

49. Tüzün A, Erdil A, Inal V, Aydin A, Bağci S, Yeşilova Z, Sayal A, Karaeren N and Dağalp K: Oxidative stress and antioxidant capacity in patients with inflammatory bowel disease. Clin Biochem 35: 569-572, 2002.

50. Pravda J: Radical induction theory of ulcerative colitis. World J Gastroenterol 11: 2371-2384, 2005.
51. Ayala A, Muñoz MF and Argüelles S: Lipid peroxidation: Production, metabolism, and signaling mechanisms of malondialdehyde and 4-hydroxy-2-nonenal. Oxid Med Cell Longev 2014: 360438, 2014

52. Boots AW, Haenen GR and Bast A: Health effects of quercetin: From antioxidant to nutraceutical. Eur J Pharmacol 585: 325-337, 2008.

53. Button LA, Roberts SE, Goldacre MJ, Akbari A, Rodgers SE and Williams JG: Hospitalized prevalence and 5-year mortality for IBD: Record linkage study. World J Gastroenterol 16: 431-438, 2010.

54. Grisham MB and Yamada T: Neutrophils, nitrogen oxides, and inflammatory bowel disease. Ann NY Acad Sci 664: 103-115, 1992.

55. Sartor RB: Cytokines in intestinal inflammation: Pathophysiological and clinical considerations. Gastroenterology 106: 533-539, 1994.

56. Elson CO, SartorRB, Tennyson GS and Riddell RH: Experimenta models of inflammatory bowel disease. Gastroenterology 109 : 1344-1367, 1995

57. Zhang JM and An J: Cytokines, inflammation and pain. Int Anesthesiol Clin 45: 27-37, 2007.

58. Sanchez-Munoz F, Dominguez-Lopez A and Yamamoto-Furusho JK: Role of cytokines in inflammatory bowel disease. World J Gastroenterol 14: 4280-4288, 2008.

59. Suzuki A, Hanada T, Mitsuyama K, Yoshida T, Kamizono S, Hoshino T, Kubo M, Yamashita A, Okabe M, Takeda K, et al: CIS3/SOCS3/SSI3 plays a negative regulatory role in STAT3 activation and intestinal inflammation. J Exp Med 193: 471-481, 2001.

60. Stucchi A, Reed K, O'Brien M, Cerda S, Andrews C, Gower A, Bushell K, Amar S, Leeman S and Becker J: A new transcription factor that regulates TNF-alpha gene expression, LITAF, is increased in intestinal tissues from patients with $\mathrm{CD}$ and UC. Inflamm Bowel Dis 12: 581-587, 2006.

61. Tahan G, Aytac E, Aytekin H, Gunduz F, Dogusoy G, Aydin S, Tahan V and Uzun H: Vitamin E has a dual effect of anti-inflammatory and antioxidant activities in acetic acid-induced ulcerative colitis in rats. Can J Surg 54: 333-338, 2011.

62. Ashry KM, El-Sayed YS, Khamiss RM and El-Ashmawy IM: Oxidative stress and immunotoxic effects of lead and their amelioration with myrrh (Commiphora molmol) emulsion. Food Chem Toxicol 48: 236-241, 2010.

63. Al-Rejaie SS: Effect of oleo-gum-resin on ethanol-induced hepatotoxicity in rats. J Med Sci 12: 1-9, 2012.

64. RahmanMM,GarveyM,Piddock LJandGibbons S: Antibacterial terpenes from the oleo-resin of Commiphora molmol (Engl.). Phytother Res 22: 1356-1360, 2008.

65. Brieskorn $\mathrm{CH}$ and Noble P: Three new furanogermacrenes from myrrh. Tetrahedron Lett 21: 1511-1514, 1980.

66. Dolara P, Luceri C, Ghelardini C, Monserrat C, Aiolli S, Luceri F, Lodovici M, Menichetti S and Romanelli MN: Analgesic effects of myrrh. Nature 379: 29, 1996.

67. Tariq M, Ageel AM, Al-Yahya MA, Mossa JS, Al-Said MS and Parmar NS: Anti-inflammatory activity of Commiphora molmol. Agents Actions 17: 381-382, 1986.

68. Tipton DA, Lyle B, Babich $\mathrm{H}$ and Dabbous MKh: In vitro cytotoxic and anti-inflammatory effects of myrrh oil on human gingival fibroblasts and epithelial cells. Toxicol In vitro 17: 301-310, 2003 